\title{
Do julgamento professoral às avaliações externas, que fazemos com as crianças e jovens na escola? Um estudo de caso na cidade de Manaus-AM
}

\author{
Camila Ferreira da Silva ${ }^{1}$ (D) ; Cecília Acácia da Silva Sampaio ${ }^{1}$ (D) ; Thiago Felippe Paranatinga da Cunha \\ ${ }^{1}$ Universidade Federal do Amazonas (UFAM), Brasil.
}

Resumo. O presente artigo ocupa-se das avaliações educacionais externas de larga escala e seus efeitos no cotidiano escolar. O cenário material no qual nosso estudo se situa diz respeito às transformações que marcaram as últimas três décadas no cenário educativo brasileiro responsáveis pela mudança na tônica da avaliação da aprendizagem no interior das escolas em direção à onipresença das avaliações externas - com especial atenção aos movimentos de constituição de um macrossistema nacional de avaliação da educação e da multiplicação de outros sistemas locais. Com o objetivo de refletir sobre as implicações das avaliações de larga escala para os educandos, ocupamo-nos dos sistemas avaliativos estadual e municipal do estado do Amazonas e de sua capital: trata-se do Sistema de Avaliação do Desempenho Educacional do Amazonas (SADEAM) e da Avaliação do Desempenho do Estudante (ADE). A partir de um estudo de caso de uma escola estadual localizada na Zona Oeste de Manaus, com base nos resultados alcançados no SADEAM (2011-2015), foi possível compreender a relação existente entre a realização das avaliações de larga escala e o processo de ensino- aprendizagem das crianças nas escolas manauaras.

Palavras-chave: avaliação educacional; avaliação de larga escala; SADEAM; ADE.

De la evaluación de los profesores a las evaluaciones externas, ¿qué hacemos con los niños y jóvenes en la escuela? Un estudio de caso en la ciudad de Manaus-AM

Resumen. . Este artículo versa sobre las evaluaciones educativas externas a gran escala y sus efectos en la vida diaria escolar. El escenario material en el que se enmarca nuestro estudio se refiere a las transformaciones que han marcado las tres últimas décadas en el escenario educativo brasileño, responsables del cambio de énfasis de la evaluación de los aprendizajes en las propias escuelas hacia la omnipresencia de las evaluaciones externas, con especial atención a los movimientos de constitución de un macrosistema nacional de evaluación de la educación y la multiplicación de otros sistemas locales. Con el fin de reflexionar sobre las implicaciones de las evaluaciones a gran escala para los estudiantes, vamos a analizar los sistemas de evaluación estatales y municipales del estado de Amazonas y su capital: el Sistema de Evaluación del Desempeño Educativo de Amazonas (SADEAM) yel Sistema de Evaluación del Desempeño de los Estudiantes ( $A D E$ ). A partir de un estudio de caso de una escuela estatal situada en la zona occidental de Manaos, basado en los resultados obtenidos en el SADEAM (2011-2015), pudimos comprender la relación entre las evaluaciones a gran escala y el proceso de enseñanza-aprendizaje de los niños en las escuelas de Manauara.

Palabras clave: evaluación educativa; evaluación a gran escala; SADEAM; ADE.

From teacher judgment to external assessments, what do we do with children and young people at school? A case study in the city of Manaus-AM

Abstract. This article deals with large-scale external educational assessments and their effects on school life. The material scenario in which our study is located concerns the transformations that marked the last three decades in the Brazilian educational scenario responsible for the change in the tonic of the evaluation of learning inside schools towards the ubiquity of external evaluations with special attention to the movements of constitution of a national macrosystem for the evaluation of education and the multiplication of other local systems. In order to reflect on the implications of large-scale evaluations for students, we are concerned with the state and municipal evaluation systems of the state of Amazonas and its capital: this is the Educational Performance Evaluation System of Amazonas (SADEAM) and Student Performance Assessment (ADE). From a case study of a state school located in the West Zone of Manaus, based on the results achieved in SADEAM (2011-2015), it was possible to understand the relationship between the conduct of large-scale assessments and the teaching process and learning in schools in Manaus.

Keywords: education assessment; large scale assessment; SADEAM; ADE. 


\section{Introdução}

A avaliação ocupa um lugar central nos processos educativos desde a concepção de escola moderna, faz parte do cotidiano das instituições educacionais e neste espaço expressa-se pela avaliação da aprendizagem historicamente realizada pelos professores, pelos conselhos de classe e pelas autoavaliações que passaram a ser promovidas pela gestão escolar em cenário recente. Os debates internacionais em torno dos sistemas educativos na transição das décadas de 1980 para 1990 fizeram emergir a questão da necessidade de avaliar tais sistemas no sentido de diagnosticá-los e, com isso, conseguir realizar um planejamento capaz de imprimir a noção de qualidade que se desenhava na literatura educacional especializada naquele momento. Destaca-se que esta noção de qualidade da educação estava aliada à concepção que alia educação formal ao desenvolvimento econômico e social dos países e que, portanto, toma a educação como um elemento diretamente proporcional aos processos de desenvolvimento ou subdesenvolvimento.

Este panorama de época desencadeou, para além das Conferências e Fóruns mundiais de Educação, a estruturação de políticas públicas nacionais especificamente voltadas para a avaliar a educação, bem como o desenvolvimento de sistemas de avaliação educacional próprios (Coelho, 2008). No caso do Brasil, data exatamente de 1990 o estabelecimento do Sistema Nacional de Avaliação da Educação Básica (SAEB), o qual, segundo Oliveira (2015), tem como principal função oferecer subsídios concretos para os processos de formulação, reformulação e monitoramento das políticas públicas para a Educação Básica no país. Os desdobramentos do SAEB na última década têm na construção de sistemas de avaliação educacional estaduais e municipais uma de suas expressões mais bem acabadas no sentido do alcance dos processos avaliativos de larga escala no país. Este é, pois, o cenário que serve de antessala para nosso artigo, posto que nos interessa compreender os contextos de emergência e as consequências do Sistema de Avaliação do Desempenho Educacional do Amazonas (SADEAM) e da Avaliação de Desempenho do Estudante (ADE), esta última sob gerência da Secretaria Municipal de Educação (SEMED) de Manaus.

Com o objetivo de refletir sobre as implicações das avaliações de larga escala para os educandos, este artigo se situa na Sociologia Política da Educação, e metodologicamente se caracteriza pela realização de um estudo de caso de uma escola estadual localizada na cidade de Manaus - Zona Oeste, com base em uma abordagem quanti-qualitativa dos resultados obtidos nas avaliações do SADEAM no período 2011-2015. Do ponto de vista da organização argumentativa, o texto encontra-se estruturado da seguinte maneira: em um primeiro momento tratamos de demarcar o descolamento histórico da avaliação da aprendizagem que ocorria no interior das escolas para a ava- 
liação da larga escala que se dá de forma externa às instituições escolares; logo depois ocupamo-nos de situar o leitor no âmbito das especificidades dos sistemas próprios de avaliação do estado do Amazonas e de sua capital; e, por fim, a última seção do texto traz a análise da escola estadual sobre a qual se desenvolveu o estudo de caso, apresentando os resultados que esta instituição obteve nas últimas edições do SADEAM, bem como colocando a questão das consequências deste tipo de avaliação para os educandos.

\section{Do julgamento professoral às avaliações externas: 0 que está em jogo?}

A ampla literatura acadêmica sobre a avaliação da aprendizagem escolar aponta o papel determinante que 0 ato de avaliar possui para a mediação pedagógica e para o acompanhamento do desenvolvimento dos educandos no cotidiano da relação que se estabelece entre professores e estudantes. Esta mesma literatura, em complementaridade a este entendimento, problematiza os sentidos que a avaliação acaba por ganhar no cotidiano escolar, em função de uma usual reprodução de concepções e práticas avaliativas tradicionais que se baseiam na dominação, no autoritarismo e tomam a avaliação como sinônimo de "exame" (Freitas, 2003; Leite \& Kager, 2009; Bourdieu \& SaintMartin, 2015; Hoffmann, 2017; Oliveira \& Medeiros, 2018). Nesse sentido, esta bifurcação que se opera no âmbito de como se compreende e como se materializa a avaliação da aprendizagem na instituição escolar é reveladora das tensões que se colocam no debate sobre a avaliação educacional e escolar.

Luckesi (2000) assevera que o ato de avaliar, como todo e qualquer ato de conhecer, inicia-se pela constatação, que nos oferece a garantia de que o objeto é como é. A relação entre avaliação e a construção de um diagnóstico situacional ganha força nesta perspectiva e nos fala do significado de qualidade educacional para as escolas, uma qualidade que figura no encalço da aprendizagem e do desenvolvimento dos educandos. Contudo, as tenções entre as diferentes significações dos processos avaliativos em contexto escolar e educacional estão na base de duas questões que se correlacionam mutuamente e que nos servem aqui e ponte para pensar as correlações entre avaliações internas e externas à escola, nomeadamente: 1) a perspectiva de avaliação como "exame", que ganhou tanto lastro na sociedade que nos permite afirmar que, das crianças aos adultos, se perguntarmos sobre o que é a avaliação no contexto da escola obteremos respostas que tratarão de elementos como "provas", "testes", "notas", "aprovação" ou "reprovação"; e 2) a reprodução deste mesmo olhar examinatório nas avaliações de larga 
escala, a partir dos mecanismos de hierarquização de instituições e sujeitos escolares, e de sistemas escolares e suas respectivas cidades, estados, regiões e países.

Para compreender esta avaliação como exame, primeiramente se faz necessário olhar para o trabalho de avalição dentro das escolas, no qual se destaca a ação do professor quando, em função do modo como historicamente tem se estabelecido o ato de avaliar nessas instituições, precisa reunir todos os dados e estabelecer uma nota e, assim, julgar a criança, o jovem ou 0 adulto que desempenha papel de estudante no ambiente educacional. Este movimento deu origem ao termo "juízo professoral", que busca sintetizar o poder simbólico que a avaliação implica. Tal juízo que recai sobre os alunos, como sabemos, não se limita somente a analisar o aprendizado e desenvolvimento individual, mas também se importa, de maneira tácita e até inconsciente, em ponderar as capacidades intelectuais, físicas e até sociais de cada educando, ao passo que extrapola a sala de aula, a relação pedagógica e os objetivos propriamente educativos. Para Bourdieu e SaintMartin (2015, p. 188):

[...] as taxinomias, que as fórmulas rituais, dos considerandos do julgamento professoral ("as apreciações") revelam e que se pode supor estruturam o julgamento professoral na medida em que o exprimem, podem ser colocadas em relação com a sanção numerada (a nota) e com a origem social dos alunos que fazem o objeto dessas duas formas de avaliação.

O juízo que o professor realiza parte de sua compreensão do sujeito aluno e da forma que este deve agir e se apresentar perante ao corpo docente e à escola, mas essa imagem perfeita e idealizada de aluno, na qual todos os educandos buscam a duras penas se enquadrar, é fruto de uma ideologia de homogeneidade aplicada, ensinada e reproduzida diretamente ou indiretamente pelas experiências e pela formação docente, visando um padrão de educandos que se afasta quase que completamente da realidade. 0 educador exprime um juízo, neste modelo hegemônico de avaliação, como parte do processo educacional e é dele a responsabilidade de analisar o desempenho de seus alunos, tarefa realizada não somente comtemplando a performance do indivíduo que está em avaliação no âmbito dos saberes construídos, mas também as características da hexis corporal, que remetem necessariamente à história, à classe social, às disposições culturais incorporadas pelos educandos (Bourdieu \& Saint-Martin, 2015).

Vale a pena destacar que este processo de julgamento professoral não revela apenas o sistema de classificações que se materializa no interior das instituições escolares na relação pedagógica entre professores e estudantes, ele nos fala de uma questão mais ampla, posto que é uma das formas de 
julgamento social a que estamos submetidos hodiernamente. Trata-se, então, de uma questão social, mais especificamente de relações sociais construídas necessariamente sobre processos de distinção e hierarquização sociais: os sujeitos são apartados socialmente, para além das questões objetivas que são mais facilmente observáveis a olhos nu na figuração social, por sistemas de classificação simbólicos que atravessam as diferentes instituições sociais, inclusive a escola e as demais instituições educacionais (Bourdieu, 2007).

Interessa-nos demarcar um movimento pendular entre as avaliações da aprendizagem que ocorrem no contexto escolar e aquelas que passaram a ser praticadas a nível das políticas públicas e que visam escrutinar os sistemas educacionais, as avaliações de larga escala. 0 movimento de julgamento que historicamente partira das mãos do professor em direção ao aluno (avaliação interna) ganha continuidade e novas roupagens no julgamento no qual as escolas passam a ser avaliadas de modo geral por órgãos internacionais, nacionais, estaduais e municipais (avaliação externa). Os sistemas de avaliação da educação, que têm se espalhado globalmente desde a década de 1990, ao selecionarem níveis, etapas e anos da educação básica e superior para estudar o desempenho, satisfação e cumprimento de metas previamente estabelecidas, incorrem na reprodução dos sistemas de classificação das instituições, sujeitos escolares e até de diferentes contextos e sistemas educativos.

Segundo Alavarse; Machado e Arcas (2017, p. 1358),

As avaliações externas têm como um de seus principais componentes a aferição do desempenho dos alunos em provas padronizadas e comtempla um amplo contingente de participantes, por isso, também, denominada na literatura como avaliação em larga escala, fornecendo em conjunto de informações que pode orientar ações das mais variadas ordens nas políticas educacionais [...].

Levando-se em consideração o papel crucial deste tipo de avaliação para o planejamento de políticas educacionais - já destacado na literatura (Klinger, Deluca \& Miller, 2008; Castro, 2009) -, o uso que tem sido feito de seus resultados segue, por vezes, uma lógica fortemente classificatória. Falar, pois, sobre julgamento neste primeiro momento é crucial para nosso debate no sentido de se entender o movimento ao qual educação escolar está submetida, e que muitas vezes ocorre de forma um tanto invisível ao hierarquizar alunos, escolas, zonas geográficas, municípios, estados, países e assim por diante. Para Oliveira e Medeiros (2018, p. 721):

[...] as classificações deles decorrentes [dos exames escolares], constituem para Bourdieu uma ocasião privilegiada para se observar a arbitrariedade pedagógica, bem como a ocultação de tal arbitrariedade. Revelam a lógica 
de funcionamento do sistema de ensino, cujas avaliações demonstram, ao olhar mais atento, o que está em jogo são não somente os conhecimentos e habilidades efetivamente ensinados, mas também um conjunto de normas implícitas, de critérios difusos e inconscientes da percepção social, que configuram um verdadeiro julgamento de classe e da relação com a cultura, a partir dos parâmetros da classe dominante.

Com isso, evidencia-se que este cenário privilegia um processo de conformação das instituições, dos professores e dos estudantes às avaliações, internas e externas à escola, o que se expressa pela importância delegada aos números, às metas, às posições que cada um vai ocupar e à comparação entre diferentes instituições e contextos. 0 caso do Brasil pode ser tomado à análise como um retrato de todo este processo, constituindo apropriada antessala para o caso do estado do Amazonas e de sua capital, Manaus.

Com múltiplas influências de debates internacionais, fóruns e conferências e ainda de organismos internacionais (Lima \& Gandin, 2019), - Brasil estrutura em 1990 o Sistema Nacional de Avaliação da Educação Básica (SAEB) e, desde então, promove avaliações sistemáticas da educação escolar no país e, com isso, compõe o Índice de Desenvolvimento da Educação Básica (IDEB). Ao longo do tempo este sistema foi sendo modificado de acordo com as demandas de cada panorama de época, oscilando entre as séries e as áreas sobre as quais suas avaliações incidiam - como exemplo temos que em 2019, seguindo as exigências da Base Nacional Comum Curricular (BNCC), passou a avaliar, além de Português e Matemática, os componentes curriculares das áreas de Ciências da Natureza e Ciências Humanas no $9^{\circ}$ ano (Oliveira, 2015).

A literatura nacional evidencia que a avaliação de larga escala no Brasil, da década de 1990 aos dias atuais, acabou por consolidar sistemas de avaliação decorrentes de suas experiências federal, estadual e municipal, o que nos permite ratificar, juntamente com Castro (2009), que existe, então, um macrossistema de avaliação da qualidade da educação brasileira. Este macrossistema comporta frentes heterogêneas de avaliação nos dois níveis educacionais, Educação Básica e Educação Superior, e oferece suporte para o delineamento e monitoramento de políticas públicas educacionais (Souza, 2011). Os limites do conjunto dessas avaliações também figuram na literatura especializada, demonstrando que os inegáveis avanços têm esbarrado na timidez do uso dos resultados das avaliações para as escolas, para os docentes e para os educandos (Gatti, 2014).

No caso do estado do Amazonas, a exemplo de outros estados brasileiros, as avaliações internacionais e nacionais desembocaram na necessidade de construção de um sistema próprio para avaliar a educação. O Sistema de 
Avaliação do Desempenho Educacional do Amazonas (SADEAM), criado em 2008 pela SEDUC-AM, e a Avaliação de Desempenho do Estudante (ADE), criada em 2014 pela SEMED-Manaus, constituem expressões desse processo de descentralização no âmbito da política de avaliação da educação no país. O nível de gradação que acaba por se materializar no conjunto das avaliações nacional, estadual e municipal coloca as instituições e os sujeitos escolares no estado do Amazonas em constantes atividades didático-pedagógicas de preparação para as diferentes avaliações, o que naturalmente modifica o cotidiano escolar e, consequentemente, impacta os processos de ensino e aprendizagem - é, pois, sobre o cenário manauara que nos debruçaremos nos próximos tópicos com vistas a compreender os principais desdobramentos desses processos avaliativos.

O movimento pendular que destacamos no início deste tópico nos mostra que o alcance dos processos avaliativos na educação sofreu um deslocamento: de dentro para fora da escola. As consequências deste movimento expressam-se tanto na centralidade quanto no alcance da avaliação educacional de larga escala, se antes o foco estava no processo pedagógico e na relação professor-estudante para pensarmos a aprendizagem e a construção de conhecimento, agora deparamo-nos com uma onipresença da avaliação, que tem gerado, entre outras questões, uma necessidade de preparação para os testes que compõem estes sistemas avaliativos, um desvirtuamento do cotidiano escolar e a subjugação dos objetivos escolares, sobretudo aqueles ligados à aprendizagem e ao desenvolvimento dos educandos, em benefício de uma preparação direcionada unicamente para a obtenção de bons resultados nas avaliações externas.

E, do ponto de vista do julgamento tácito dos processos de avaliação educacional que destacamos inicialmente, tem-se que ele se alastra e alargase na mesma medida do alcance dessas avaliações de larga escala. Se antes a literatura preocupava-se com os efeitos do julgamento professoral sobre os educandos, hoje, para além disso, coloca-se imperativamente a necessidade de refletir acerca das consequências de um julgamento social generalizado sobre as escolas, os profissionais da educação que nela trabalham e, mais uma vez, sobre os educandos.

\section{Situando as avaliações educacionais externas no cenário amazonense}

Os estudos acerca da implementação das avaliações externas no Brasil começaram a ser realizados no final dos anos 1980, por influência de outros países que também iniciaram o processo de introdução de sistemas 
de avaliações educacionais, o foco neste momento residia na economia e na relação entre Educação e Desenvolvimento. Tais iniciativas voltadas para a educação estavam fundamentadas nas políticas neoliberais que começaram a ganhar força no final da década de 1970 em países como Inglaterra e Estados Unidos, que possuíam governos de direita.

Essas políticas neoliberais surgem como estratégias para limitar as funções do Estado e tornar o mercado econômico o centro da vida social, valorizando os processos de privatizações de setores públicos e a competitividade a nível internacional. Na educação, enquanto setor privilegiado nesta perspectiva de relação direta entre o investimento em educação e o nível de desenvolvimento das nações, o mesmo caminho fora trilhado e, para tal, dentre outras frentes, há a implementação de sistemas avaliativos em larga escala com vistas a garantir uma qualidade competitiva, a nível global, dos sistemas de educação nacionais.

Ao aderir a esse tipo de estratégia, os sistemas educacionais em diferentes contextos geográficos, sociais, econômicos e políticos ao redor do mundo colocam-se na fronteira da noção de "quase-mercado", que, segundo define Julian Le Grand (1991), é a substituição do monopólio do Estado por vários outros fornecedores concorrentes e autônomos que pretendem não necessariamente obter o lucro através de tais medidas, mas sim conseguir cada vez mais clientes (Afonso, 1999). Consequentemente, a adoção do quase-mercado dentro dos sistemas educacionais públicos é vantajoso somente para o mercado, já que há a diminuição de gastos para este, havendo um controle maior das contas públicas e a redução dos gastos destinados à educação. Além disso, por meio das avaliações externas, o mercado pode controlar o currículo e os conteúdos ministrados nas escolas, com a ênfase no incentivo à competição e à concorrência entre as instituições em níveis nacionais e internacionais na busca por melhores desempenho e resultados. Desse modo, as escolas acabam se tornando verdadeiras empresas, "[...] inclui-se todo o processo educacional na esfera do mercado e generalizam-se os procedimentos e valores típicos do capitalismo competitivo na gestão dos sistemas e das instituições educacionais" (Souza \& Oliveira, 2003, p.874).

A primeira experiência com as avaliações em larga escala no Brasil ocorreu em 1990, quando foi criado pelo Ministério da Educação (MEC) o SAEB. "O sistema visava, inicialmente, conhecer as falhas e ou deficiências do contexto educacional brasileiro e, assim, obter um diagnóstico" (Nogueira, 2018, p.25). A partir daí, novas mudanças em relação ao objetivo dessa avaliação começaram a ser realizadas, como por exemplo, em 1993 a avaliação passou a conferir um foco maior ao perfil dos estudantes e às práticas dos professores, assim como também à gestão escolar; ou mesmo as reformulações mais recentes em decorrência da BNCC, que citamos no tópico anterior. 
Após a criação do SAEB, outras avaliações externas passaram a figurar também no Brasil, a exemplo de muitos outros países do Sul global. Tais avaliações foram supostamente elaboradas visando medir o nível de desempenho dos estudantes brasileiros das escolas públicas e privadas e, por meio desses resultados, traçar novas estratégias que possibilitassem a melhoria da qualidade educacional no país. Autores como Lima e Gandin (2019) e Coelho (2008) alertam para este cenário de influências externas ou transnacionais nos processos de consolidação de uma hegemonia de discursos e práticas em favor das avaliações de larga escala no Brasil - destacam-se elementos como: o estabelecimento de compromissos com os parâmetros internacional para a educação, a influência de organismos internacionais e a dependência transnacional tanto monetária quanto de modelo de sistema educacional.

É exatamente neste cenário que o SAEB se consolida e passa a fazer parte do cotidiano das instituições escolares em todo o Brasil, figurando como uma instância que determina, dentre outros fatores, a organização didática e pedagógica para o cumprimento das metas estabelecidas. Um dos desdobramentos deste macrossistema de avaliação da educação no país reside na instituição de políticas educacionais de avaliação de larga escala a níveis estadual e municipal.

No caso do Amazonas, o primeiro sistema de avaliação deste tipo fora criado em 2008 com o intuito de avaliar o desempenho dos estudantes amazonenses, estamos a falar do Sistema de Avaliação do Desempenho Educacional do Amazonas (SADEAM). Posteriormente, outras avaliações foram sendo implementadas no estado, inclusive na capital, Manaus, que passou a ter seu próprio sistema de avaliação para averiguar o desempenho dos estudantes manauaras matriculados nos anos iniciais e finais do ensino fundamental e EJA da rede municipal. Esse sistema foi denominado de Avaliação de Desempenho do Estudante (ADE), criado em 2014 pela SEMED-Manaus e tem sido considerado o "[...] projeto pioneiro da SEMED, com o objetivo de avaliar o desempenho dos estudantes e auxiliar diretores, pedagogos e professores no monitoramento dos processos pedagógicos de ensino e aprendizagem a partir da análise dos resultados obtidos" (Breves, Rocha \& Monteconrado, 2017, p.16223-16224).

O SADEAM e a ADE, juntamente com os outros sistemas de avaliação em larga escala do país, formam um macrossistema de avaliações voltado para a performance da Educação Básica no Brasil. Desse modo, pode-se observar uma relação histórico-política entre esses diferentes sistemas de avaliação, o que nos auxilia a compreender o lugar e o papel dos sistemas estadual e municipal do Amazonas e de Manaus: 
Figura 1. Correlações temporais para compreender o SADEAM e a ADE

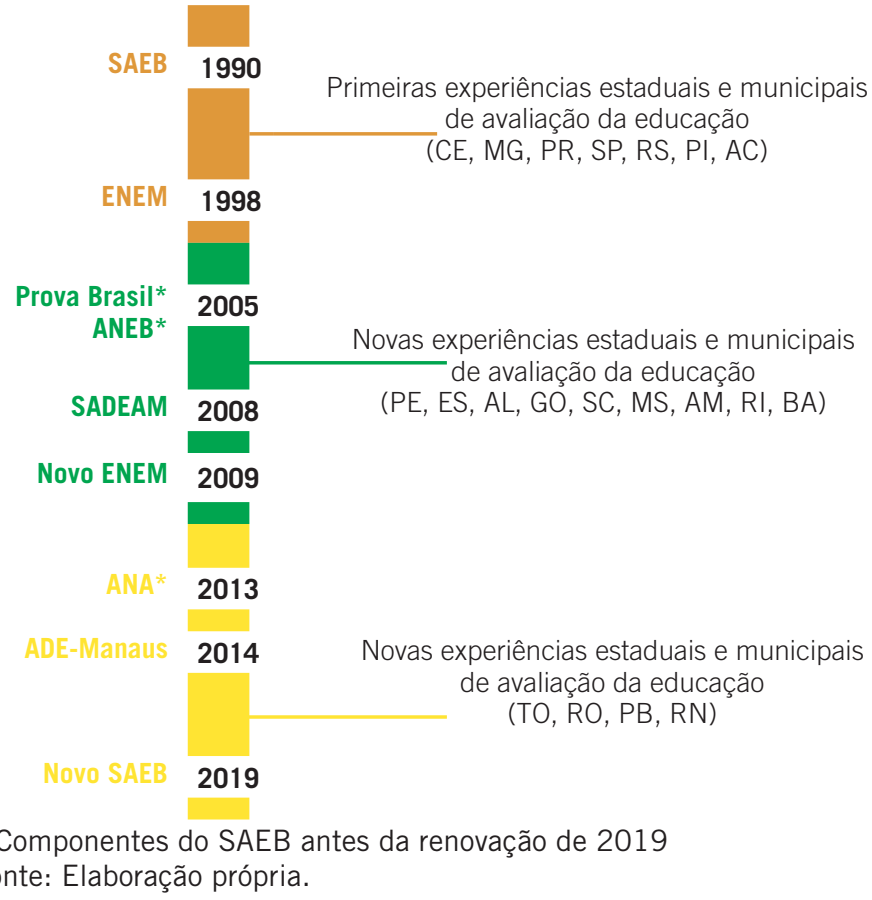

Antes da renovação do SAEB, anunciada em junho de 2019 e ainda em curso, a Avaliação Nacional de Rendimento Escolar (ANRESC) - também conhecida como Prova Brasil -, a Avaliação Nacional da Educação Básica (ANEB) e a Avaliação Nacional da Alfabetização (ANA) compunham o SAEB. Juntas estas avaliações fornecem o IDEB, que, por sua vez, é considerado um importante indicador censitário da qualidade educacional do país, no entanto, há contradições acerca do seu real objetivo para Educação Básica. Jesus et al. (2017, p. 219) afirmam que:

Ao mesmo tempo que a avaliação é necessária como parte do processo pedagógico em sala de aula, é tema controverso quando se trata de avaliação do sistema de ensino porque pode ser tratada desde o ponto de vista didático até questões sociais e políticas que ultrapassam as instituições de ensino e tomam dimensões internacionais de relações de poder. Em síntese, ao Ideb é concedida atribuição de sumarizar a qualidade de ensino oferecida a partir desses dois fatores não parece viável, já que incapaz de refletir a realidade das instituições.

Tais relações de poder nos levam a destacar os limites de um índice como o IDEB, posto que não consegue abarcar em seu espectro quantitativo a complexidade, a diversidade e as especificidades das escolas brasileiras, ao passo que, com a divulgação das médias e resultados finais, acaba por ratificar a cultura classificatória no âmbito das instituições de ensino. Dessa 
maneira, percebe-se que a preocupação economicista ganha centralidade, a exemplo do cenário inicial da relação educação-desenvolvimento que tratamos inicialmente neste tópico, e a relação com o mercado se sobressai em detrimento de uma formação cidadã na qual a qualidade [ou o educando e a escola] não se reduz a um índice. Prova disso é que as avaliações que servem até então de base para o IDEB medir o nível educacional no país centram-se somente nas disciplinas de Português e Matemática. Em relação a isso, para Sousa (2014, p.412), a ênfase nestas duas disciplinas "[...] induz a um movimento de homogeneização do que se ensina em todo o Brasil".

Tomando o SADEAM à análise, e aqui pensando a especificidade do estado do Amazonas, tem-se que este sistema avaliativo avalia os estudantes não só em Língua Portuguesa e Matemática, mas também nas áreas de Ciências Humanas e Ciências da Natureza. Entretanto, é importante ressaltar que as avaliações feitas nas áreas de Ciências da Humanas e da Natureza são destinadas apenas para os alunos do Ensino Médio e Educação de Jovens e Adultos (EJA). No primeiro ano de aplicação do SADEAM, em 2008, foram realizadas provas com os estudantes matriculados nos $5^{\circ}$ e $9^{\circ}$ anos do Ensino Fundamental, sendo avaliados em Português e Matemática e para os estudantes do $3^{\circ}$ ano do Ensino Médio e EJA foram realizadas avaliações nas disciplinas de Biologia, Química, Geografia, História, Língua inglesa e Física (Caed/UFJF, ca 2016). A última edição do SADEAM foi realizada em 2019, e nesta edição as provas foram aplicadas para os alunos do $4^{\circ}$ e $7^{\circ}$ anos do Ensino Fundamental I e para o $1^{\circ}$ ano do Ensino Médio - contudo, destaca-se que os resultados disponibilizados na página eletrônica oficial do SADEAM ${ }^{1}$ abarcam somente o período de 2011 a 2015, o que provavelmente está atrelado à parceria estabelecida com o Centro de Políticas e Avaliação da Educação (CAEd), instituição que faz parte da Universidade Federal de Juiz de Fora (UFJF), a partir de 2011.

No caso da ADE, e aqui falamos especificamente da cidade de Manaus, há também esta marca de contemplar áreas do saber para além da Língua Portuguesa e da Matemática,

Nos anos de 2014 a 2017 foram avaliados por meio da ADE, estudantes do ensino fundamental dos anos iniciais e finais ( $3^{\circ}$ ao $9^{\circ}$ anos), nos componentes curriculares de Língua Portuguesa e Matemática, além de Ciências da Natureza e Humanidades (para o $8^{\circ} / 9^{\circ}$ anos), com três aplicações ao ano, tendo como elementos estruturantes dos testes os documentos supracitados e outros afins. Em 2018, optou-se por avaliar o desempenho dos estudantes dos $3^{\circ}, 4^{\circ}, 6^{\circ}$ e $8^{\circ}$ anos em três momentos, da Educação de Jovens e Adultos-EJA, da $3^{\mathrm{a}}$ e $4^{\mathrm{a}}$ fases em duas aplicações e do Projeto Itinerante uma aplicação no decorrer do ano letivo somente

${ }^{1}$ http://www.sadeam.caedufjf.net/. 
nos componentes curriculares de Língua Portuguesa e Matemática, por entender que o MEC/Inep construirá as matrizes de referências concernentes aos componentes curriculares Ciências da Natureza e Ciências Humanas, alicerçada a Base Nacional Comum Curricular, com aplicação para 2019 (Semed-Manaus, ca 2019, para 4-5).

Observa-se, então, que a $A D E$ atualmente não abarca os $1^{\circ}$ e $2^{\circ}$ anos do Ensino Fundamental, centrando-se, pois, no intervalo compreendido entre $3^{\circ}$ e $9^{\circ}$ anos desta etapa de ensino. Destaca-se ainda que em sua página eletrônica oficial da Divisão de Avaliação e Monitoramento², onde encontramse as informações sobre a $A D E$, não são disponibilizados os resultados das edições desta avaliação (2014-2019) - sendo este um elemento concreto que incidiu sobre a nossa escolha para a realização do estudo de caso nesta pesquisa, pelo que tivemos que trabalhar com os dados do SADEAM, os quais encontram-se disponíveis atualmente.

Ademais, compreendendo as relações históricas e políticas que servem de antessala para a construção do SADEAM e da ADE, em um cenário de consolidação do próprio SAEB no Brasil e das ingerências internacionais sobre a noção de qualidade dos sistemas educativos em países do Sul global, selecionamos uma escola estadual da capital amazonense, localizada na Zona Oeste e que atende estudantes do $1^{\circ}$ ao $5^{\circ}$ ano do Ensino Fundamental, para a realização de um estudo de caso. Nosso objetivo com tal estudo de caso é construir uma reflexão aprofundada sobre a instituição em questão e tomála como expressão das consequências das avaliações de larga escala para o cotidiano das crianças e jovens nas escolas do estado do Amazonas.

\section{Estudo de caso de uma escola da Zona Oeste de Manaus e as implicações das avaliações de larga escala para crianças e jovens nas escolas}

Tomar uma escola à análise, com base nos resultados obtidos em uma avaliação de larga escala implica esclarecer dois elementos que se colocam de forma apriorística em nossa análise, a saber: i) não realizaremos uma leitura presa somente aos dados quantitativos, tampouco com uma mirada hierarquizante comparando diferentes escolas, nosso interesse centra-se em, a partir dos dados, problematizar os processos de ensino e aprendizagem nas escolas de Manaus no cenário de onipresença das avaliações de larga escala; ii) o estudo de caso aqui realizado busca, por intermédio da experiência de uma escola, pensar o conjunto mais amplo das relações pedagógicas que acabam por se transformar neste cenário.

\footnotetext{
${ }^{2}$ https://bit.ly/3jEbLtH.
} 
De maneira geral, quando tomamos a realidade do Amazonas, e mais especificamente de Manaus, à análise, vale a pena chamar atenção para a tentativa de - com os sistemas estadual e municipal de avaliação da educação - melhorar os índices do estado e de sua capital em avaliações outras, nos cenários nacional e internacional. Nesse sentido, a espiral de diferentes avaliações que incidem sobre as escolas, os gestores, os professores e sobre os educandos e suas famílias merece reflexões no sentido de compreender seus efeitos.

Henchen e Brasil (2017), ao analisarem os resultados das avaliações externas na cidade de Manaus, apontam algumas questões que se revelam importantes para nosso debate, a saber: elementos como infraestrutura das escolas, acesso, problemas sociais enfrentados pelos estudantes e pela comunidade escolar de maneira geral provocam reflexos no cotidiano dos alunos e, por sua vez, incidem direta ou indiretamente nos resultados obtidos; vem ocorrendo um movimento de padronização nos registros das ações por parte das escolas avaliadas, o que significa uma acentuada preocupação com os índices e um descompasso com a realidade vivenciada em função do objetivo de se alcançar um resultado considerado satisfatório; as escolas com jornada ampliada lidam com metas altas e têm conseguido responder à altura, o que coloca em xeque os casos das instituições com jornadas menores, esta discrepância acaba por produzir um discurso em prol de maior dedicação de tempo para a preparação dos alunos para essas avaliações - percebe-se, portanto, que se adota uma preocupação com os resultados e não necessariamente com a qualidade do ensino, já que o tempo de aplicação das atividades escolares passa ser reduzindo aos objetivos das avaliações externas e passa a atender somente uma ordem sistêmica de cumprimento de rankings.

Aliado a isso, os estágios curriculares e aqueles não-obrigatórios, bem como as experiências com o Programa Institucional de Bolsa de Iniciação à Docência (PIBID) e com a Residência Pedagógica, ao colocarem os acadêmicos das licenciaturas em contato direto com a realidade das escolas estaduais de Manaus, têm promovido uma observância em torno do lugar que as avaliações de larga escala têm ocupado no cotidiano dessas escolas. Nota-se uma ênfase nos processos de preparação das crianças e jovens para as provas que compõem as avaliações locais e nacionais, pelo que as necessidades de aprendizagem dos educandos, muitas vezes, são deixadas de lado, especialmente em tempos em que essas avaliações se aproximam.

O deslocamento pendular da aprendizagem e desenvolvimento dos estudantes para o treinamento para responder a essas avaliações externas vem modificando o cotidiano escolar e, consequentemente, a mediação e a relação pedagógica. Quando a avaliação de larga escala provoca uma ruptura com os processos de ensino e aprendizagem escolar e gera uma preparação 
quase que frenética para a feitura de uma prova pontual, é preciso, então, avaliar os próprios pressupostos que compõem as políticas públicas de avaliação educacional.

No caso da Escola Estadual Amarela- nome fictício que utilizaremos a partir deste momento para tratar da escola estudada -, localizada no bairro São Jorge na Zona Oeste de Manaus e atendendo do $1^{\circ}$ ao $5^{\circ}$ ano do Ensino Fundamental (EF), promovemos uma correlação entre os resultados obtidos no SADEAM 2011-2015 nas diferentes disciplinas. 0 público atendido por esta escola é composto por crianças que se encontram matriculadas nos anos iniciais do Ensino Fundamental, a avaliação do SADEAM incidiu sobre os $3^{\circ}$ e $5^{\circ}$ anos, sempre nas disciplinas de Língua Portuguesa - no caso do $3^{\circ}$ ano esta disciplina está caracterizada como Escrita e Leitura - e Matemática. Nossa análise toma como recorte as avaliações realizadas com o $3^{\circ}$ ano do $\mathrm{EF}$, o qual, no caso da Escola Estadual Amarela, foi avaliado nas edições 2011, 2012 e 2015.

Inicialmente, tratemos do nível de envolvimento dos estudantes da Escola Estadual Amarela ao SADEAM, o qual pode ser observado pela taxa de participação nas diferentes edições com as quais estamos a trabalhar:

Tabela 1. Taxa de participação dos estudantes no SADEM (2011-2015): o caso da Escola Estadual Amarela

\begin{tabular}{|c|c|c|c|}
\hline 2011 & & & \\
\hline Disciplinas avaliadas & Participa & & \\
\hline & Previsto & Efetivo & $\%$ \\
\hline Língua Portuguesa (Escrita e Leitura) & 167 & 127 & $76 \%$ \\
\hline Matemática & 166 & 139 & $83,7 \%$ \\
\hline 2012 & & & \\
\hline Disciplinas avaliadas & Participa & & \\
\hline & Previsto & Efetivo & $\%$ \\
\hline Língua Portuguesa (Escrita e Leitura) & 177 & 144 & $81,4 \%$ \\
\hline Matemática & 177 & 163 & $92,1 \%$ \\
\hline 2015 & & & \\
\hline Disciplinas avaliadas & Participa & & \\
\hline & Previsto & Efetivo & $\%$ \\
\hline Língua Portuguesa ${ }^{1}$ & 138 & 119 & $86,2 \%$ \\
\hline Escrita & 138 & 118 & $85,5 \%$ \\
\hline Matemática & 138 & 123 & $89,1 \%$ \\
\hline $\begin{array}{l}\text { 1. Em 2015, a área anteriormente den } \\
\text { Portuguesa" e a ter seu instrumento }\end{array}$ & $\begin{array}{l}\text { " "Leitur" } \\
\text { em dia }\end{array}$ & $\begin{array}{l}\text { sou a se } \\
\text { nte da } E\end{array}$ & ada de “Língua \\
\hline Fonte: Elaboração própria, com base & d/UFJF ( & 16). & \\
\hline
\end{tabular}


Observa-se que, ao longo do período analisado há oscilações distintas quanto à participação dos estudantes nas áreas do conhecimento avaliadas na escola em questão: enquanto em Língua Portuguesa a adesão foi crescendo nesses anos, em Matemática não há uma linearidade progressiva; por outro lado, mesmo com maior grau de irregularidade nos anos analisados, é na área de Matemática que sempre há maior participação quantitativa ano a ano. De modo geral, pode-se afirmar que a participação das crianças matriculadas no $3^{\circ}$ ano do EF na Escola Estadual Amarela no SADEAM tem se revelado bastante expressiva, o que pode ter como elemento explicativo 0 apelo que as escolas passaram a fazer no sentido de garantir a presença dos estudantes quando da aplicação das provas.

Sabe-se que o SADEAM utiliza cinco elementos para compor os resultados das escolas analisadas, são eles: a matriz de referência, a teoria de resposta ao item (TRI), o caderno de testes, a escala de proficiência e os padrões de desempenho (Oliveira, 2015). As escolas são classificadas, pois, com relação ao desempenho de seus estudantes - "Abaixo do Básico", "Básico", "Proficiente" e "Avançado" constituem os padrões de desempenho desenhados no SADEAM. Nesse sentido, os resultados apontam o percentual de educandos que se encontra em cada um desses padrões, sendo o conjunto da performance dos estudantes determinante para o estabelecimento do índice de cada escola em cada uma das disciplinas avaliadas.

Os resultados da Escola Estadual Amarela podem ser sintetizados da seguinte forma:

\section{Gráfico 1. Resultados SADEAM 2011-2015: $3^{\circ}$ ano do Ensino Fundamental da Escola Estadual Amarela}

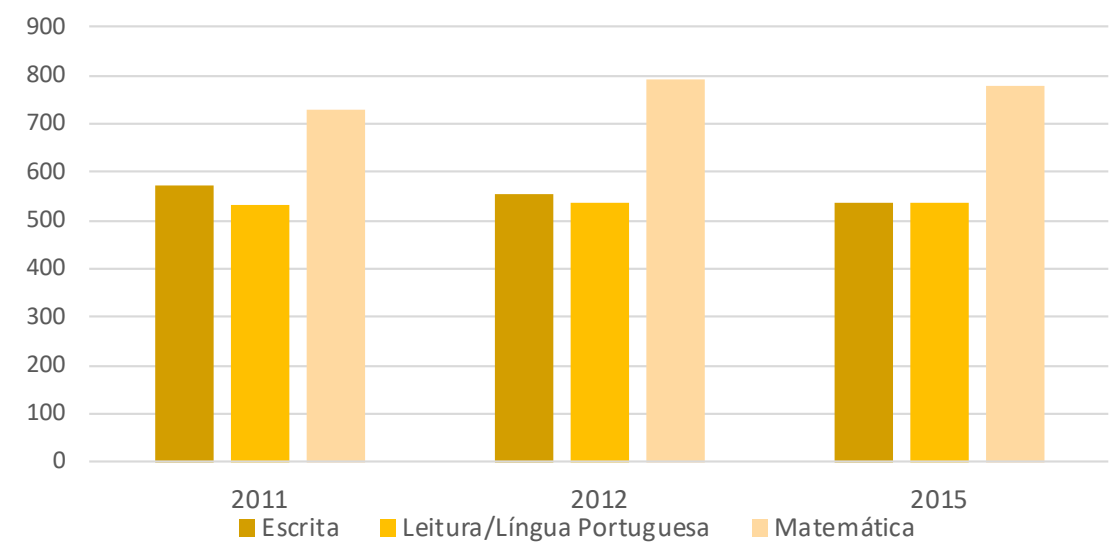

Fonte: Elaboração própria, com base em Caed/UFJF (ca 2016). 
A discrepância entre as duas grandes áreas do saber representadas no gráfico acima é notória, vale a pena destacar que ela se mantém constante para todas as escolas do estado do Amazonas que foram avaliadas no âmbito do SADEAM, e acaba por nos falar tanto das diferenças das respectivas matrizes de referência de cada uma dessas áreas, quanto do desafio histórico colocado, no Amazonas, em Manaus e no Brasil, sobre a Língua Portuguesa, a alfabetização, a leitura, escrita e a compreensão e interpretação. Com base nas matrizes de referência e nos padrões de desempenho de cada área, é curioso que em Escrita e Leitura/Língua Portuguesa tenhamos mais estudantes na categoria "Avançado", enquanto em Matemática o que se tem é que a maior parte dos estudantes do $3^{\circ}$ ano do EF da escola analisada encontram-se na categoria "Básico" (Caed/UFJF, ca2016).

Chama atenção ainda as variações nas três áreas representadas no Gráfico 1: i) vê-se que, no caso da Escrita, os anos analisados viram desenharse um movimento decrescente de quase 40 pontos entre 2011 e 2015; ii) em Leitura/Língua Portuguesa temos a área que manteve maior estabilidade nos três anos que aqui figuram em uma média de 5 pontos para mais ao final deste período; iii) já a disciplina de Matemática apresentou um salto de pouco mais de 20 pontos entre 2011 e 2012, porém, desceu quase 14 pontos de 2012 para 2015. No cenário mais amplo, faz-se mister destacar que a Escola Estadual Amarela, a exemplo de muitas outras escolas estaduais que vêm sendo avaliadas pelo SADEAM desde 2008, apresenta índices bastante próximos daqueles alcançados pelas médias do estado do Amazonas e da própria Coordenadoria Distrital de Educação (CDE) na qual está inserida ${ }^{3}$.

Diante desses dados, ao pensarmos a participação das crianças do $3^{\circ}$ ano do Ensino Fundamental nas avaliações de larga escala e a construção dos índices de uma escola específica, emerge a necessidade de interrogar os processos que envolvem a política de avaliação educacional, sobretudo no que concerne aos seus desdobramentos no contexto educacional e escolar do Amazonas. Objetivamente falando, pode-se apontar as seguintes ações encabeçadas pela SEDUC-AM na sequência ao SADEAM: a criação do Fundo Estadual de Incentivo ao Cumprimento de Metas da Educação Básica e a ligação com a política de bonificação para as escolas que atingem as metas ou, ao menos, melhoram seus índices - a exemplo do "Prêmio Escola de Valor"; a criação e implementação, em 2013, do "Programa de Intervenção Pedagógica do Amazonas" (PIPA), cujo objetivo consiste em oferecer assessoramento didático-pedagógico para as escolas com baixo desempenho no

3 Trata-se da Coordenadoria Distrital de Educação 04, que abarca escolas das Zonas Oeste e Centro-Oeste de Manaus. 
SADEAM e no SAEB; em 2011, nesta mesma linha, a secretaria constituiu o "Programa Criando Oportunidades", com vistas a garantir reforço escolar nas escolas com índices baixos; dentre outras ações (Oliveira, 2015).

Se o discurso que se legitimou desde 2008 [ano de criação do SADEAM] tem gorado em torno da melhoria da educação no estado do Amazonas, faz-se mister interrogar tanto este sistema de avaliação de larga escala, quanto as iniciativas de reforço que o seguiram no sentido de compreender suas potencialidades e seus limites. Que impactos o SADEAM, a ADE e todas as ações supracitadas têm desenhado no cotidiano das escolas?

Cabe-nos, portanto, uma reflexão em torno do que estamos a fazer com as crianças e com os jovens nas escolas neste cenário de supervalorização dos índices e das hierarquias que são construídas a partir deles. Nossos educandos da Educação Básica têm se deparado com uma formação que os coloca desde muito cedo em um processo de auto adequação às provas e testes previstos nas avaliações de larga escala. 0 brincar, a socialização, a própria interação com os pares, o trabalho colaborativo são exemplos de elementos que têm sido secundarizados, posto que a lógica do treinamento para sair-se bem nas avaliações de larga escala prevê um trabalho solitário de memorização do formato, do conteúdo e das respostas que devem ser dadas às perguntas postas nesse tipo de avaliação.

Em que pesem os avanços que a política de avaliação educacional trouxe para os processos de elaboração de novos caminhos e de monitoramento da educação nacional - e aqui a literatura especializada já destaca tais avanços e sua importância (Castro, 2009; Fontanive, 2011) -, faz-se mister compreender, por outro lado, os limites que estão postos no que usualmente ocorre quando da ampla publicação dos resultados das avaliações externas, nomeadamente: a hierarquização das instituições escolares, dos bairros, das cidades, estados e até dos países em função de sua performance nos testes aplicados, o que naturalmente implica uma hierarquia dos sujeitos que compõem essas instituições; a ratificação da cultura classificatória no campo educacional, que reproduz um sistema de classificações que distingue escolas "boas" e "ruins"; a responsabilização e culpabilização dos sujeitos escolares (gestores, professores e educandos e suas famílias) pelos resultados considerados negativos; entre outros. 


\section{Considerações Finais}

A educação vem sendo tomada, desde a Modernidade, como um elemento crucial para a ideia de desenvolvimento social e econômico dos países, o que significa necessariamente que as ações e os direcionamentos dos Estados nacionais no âmbito das políticas de educação são reveladores dos projetos de nação. As políticas públicas de avaliação da educação inseremse nesta lógica, ao passo que historicamente ligam-se a processos amplos como a mundialização, a competitividade e mercadorização da educação, bem como às influências supranacionais nos sistemas educativos dos países.

No cenário educacional brasileiro, com a criação do SAEB em 1990 houve a necessidade de diagnosticar o desempenho dos estudantes brasileiros, bem como pensar a questão da qualidade da educação no país. Posteriormente, a implementação de tal sistema avaliativo influenciou governos estaduais e municipais a criarem seus próprios sistemas de avaliação educacional de larga escala. Contudo, ao lado dos objetivos ligados à monitorização e aprimoramento da educação, o real sentido de uma avaliação diagnóstica para identificar os possíveis problemas educacionais que necessitam ser sanados levando-se em consideração as especificidades de cada instituição de ensino, tem sido secundarizado. As avaliações externas de larga escala tornaram-se, pois, ferramentas políticas elaboradas com o intuito de atingir as metas pré-estabelecidas pelo governo e por agências especializadas, acompanhando o desenvolvimento de múltiplos instrumentos avaliativos [locais, nacionais e até internacionais] para a construção de uma imagem educacional paradigmática e, por vezes, alienada da realidade e, em contrapartida, a competição, a hierarquização e a classificação, a partir dos resultados amplamente divulgados dessas avaliações externas, ganham força dentro das escolas e no imaginário social.

A adoção de tais sistemas exerce grande impacto direto na organização didático-pedagógica das instituições de ensino, uma vez que, mediante a eles, há um foco maior para o treinamento de conteúdos e habilidades que são exigidos exclusivamente por essas avaliações, o objetivo do processo de ensino-aprendizagem acaba, pois, sendo subvertido no interior das escolas, ao passo que elas são bombardeadas com múltiplas avaliações externas atualmente, passando a privilegiar os produtos dessas avaliações: os resultados, os índices e a posição frente a outras escolas. A aprendizagem e 0 desenvolvimento dos educandos são, portanto, secundarizados.

O caso da escola estadual aqui estudada acabou por demonstrar a influência de tais avaliações no cotidiano escolar das crianças matriculadas nas escolas públicas de Manaus. Nesse sentido, ratificamos a relevância de se enfrentar o debate acerca dos efeitos das avaliações externas para 0 
processo educativo. Ressalta-se que o tema abordado - seja em Manaus, em outros municípios amazonenses, e mesmo em outros estados da federação necessita de mais estudos e pesquisas para continuarmos a refletir sobre o alcance das avaliações de larga escala e sua relação com a noção socialmente referenciada de qualidade da educação.

\section{Referências}

Afonso, A. J. (1999). Estado, mercado, comunidade e avaliação: Esboço para uma rearticulação crítica. Educação \& Sociedade, 69, 139-164.

Alvarse, O. M., Machado, C. \& Arcas, P. H. (2017). Avaliação externa e qualidade da educação: formação docente em questão. Rev. Diálogo Educ., 17(54), 1353-1375.

Bourdieu, P. (2007). A Distinção: crítica social do julgamento. São Paulo/Porto Alegre, EDUSP/ Zouk.

Bourdieu, P. \& Saint-Martin, M. (2015). As categorias do juízo professoral. In Maria Alice Nogueira \& Afrânio Catani (Org.). Escritos de educação (pp. 205-241). Petrópolis, RJ: Vozes.

Brasil. Ideb. Portal do Mec. Recuperado de http://portal.mec.gov.br/conheca-o-ideb.

Breves, N. S. P., Rocha, S. E. A., \& Monteconrado, G. M. (2017). Sistema de avaliação de desempenho educacional - SADEM: experiência na rede pública municipal de ensino de Manaus. $13^{\circ}$ Congresso Nacional de Educação/EDUCERE, Curitiba. Recuperado de https://bit.ly/34Y7PxU.

Caed/UFJF. O SADEAM, Juiz de Fora, ca 2016. Recuperado de https://bit.Iy/2FpaeZF.

Castro, M. H. G. (2009). Sistemas de avaliação da educação no Brasil: avanços e novos desafios. São Paulo em Perspectiva/Fundação Seade, 23(1), 5-18.

Coelho, M. I. M. (2008). Vinte anos de avaliação da educação básica no Brasil: aprendizagens e desafios. Ensaio: Aval. Pol. Públ. Educ., 16(59), 229-258.

Fontanive, Nilma. (2011). $O$ uso pedagógico dos testes. In Alberto de M. Souza (Org.). Dimensões da Avaliação educacional (pp. 139-173). Petrópolis: Vozes, 2011.

Freitas, L. C. (2003). Ciclos, seriação e avaliação: confronto de lógicas. São Paulo: Moderna.

Gatti, B. (2014). Avaliação: contexto, história e perspectivas. Olh@res, 2(1), 08-26.

Henchen, A. K. \& Brasil, D. S. B. (2017). Os desafios ambientais das escolas do campo municipais fomentados pelo Instituto Áquila nos resultados das avaliações externas municipais da cidade de Manaus/AM. Revista Eletrônica Pesquisaeduca, 9(17), 201-211.

Hoffmann, Jussara. (2017). Avaliação: mito e desafio: uma perspectiva construtivista. Porto Alegre: Mediação.

Jesus, E. L. et al. (2017). Avaliação Educacional em Manaus-AM: o IDEB em questão. AretéRevista Amazônica de Ensino de Ciências, 10(21), 216-229. 
Klinger, D., Deluca, C. \& Miller, T. (2008). The evolving culture of large-scale assessments in Canadian education. Canadian Journal of Educational Administration and Policy, 3, 1-34.

Le Grand, J. (1991). Quasi-markets and social policy. The Economic Journal, 101, 1256-1267.

Leite, S. A. S. \& Kager, S. (2009). Efeitos aversivos das práticas de avaliação da aprendizagem escolar. Ensaio: aval. pol. públ. Educ., 17(62), 109-134.

Lima, I. G. \& Gandin, L. A. (2019). O contexto da consolidação das avaliações em larga escala no cenário brasileiro. Educ. Soc., 40, 1-28.

Luckesi, C. C. (2000). O que é mesmo o ato de avaliar a aprendizagem? Pátio On-line, 3(12), 1-7.

Nogueira, E. L. (2018). Práticas Influentes na Melhoria dos Índices educacionais: o caso de uma escola do Ensino Fundamental l em Manaus. Dissertação (Mestrado Profissional em Gestão e Avaliação da Educação Pública) - Universidade Federal de Juiz de Fora, Juiz de Fora.

Oliveira, J. M. \& Medeiros, C. C. C. (2018). Categorias do juízo professoral: entre interpretações, julgamentos e implicações. Estud. Aval. Educ., 29(72), 710-737.

Oliveira, S. M. S. (2015). O Sadeam e o Ensino de Língua Portuguesa em duas Escolas de Manaus: Implicações do fazer pedagógico para o Letramento. Dissertação (Mestrado Profissional em Gestão e Avaliação da Educação Pública), Faculdade de Educação, Universidade Federal de Juiz de Fora, Juiz de Fora.

Semed-Manaus. ADE, Manaus, ca 2019. Recuperado de https://bit.ly/3ixDD1a.

Souza, A. M. (Org.). (2011). Dimensões da Avaliação educacional. Petrópolis: Vozes.

Sousa, S. Z. (2014). Concepções de Qualidade da Educação Básica Forjadas por meio de Avaliações em Larga Escala. Avaliação, 19(2), 407-420.

Souza, S. Z. \& Oliveira, R. P. (2003). Políticas de Avaliação da Educação e Quase Mercado no Brasil. Educ. Soc., 24(84), 873-895. 